\title{
The pathogenic potential of Helicobacter cinaedi isolated from non-human sources: adherence, invasion and translocation ability in polarized intestinal epithelial Caco-2 cells in vitro
}

\author{
Takako TANIGUCHI ${ }^{1,2)}$, Wataru YAMAZAKI ${ }^{1,2)}$, Yuji SAEKI ${ }^{3)}$, Ichiro TAKAJO ${ }^{4)}$, Akihiko OKAYAMA ${ }^{4)}$, \\ Tetsuya HAYASHI ${ }^{5,6)}$ and Naoaki MISAWA ${ }^{1,2) *}$ \\ ${ }^{1)}$ Laboratory of Veterinary Public Health, Department of Veterinary Medical Science, Faculty of Agriculture, University of Miyazaki, 1-1 \\ Gakuenkibanadai-nishi, Miyazaki 889-2192, Japan \\ ${ }^{2)}$ Center for Animal Disease Control, University of Miyazaki, 1-1 Gakuenkibanadai-nishi, Miyazaki 889-2192, Japan \\ ${ }^{3)}$ Clinical Laboratory, University of Miyazaki Hospital, 5200 Kiyotake, Miyazaki 889-1692, Japan \\ 4) Department of Rheumatology, Infectious Diseases and Laboratory Medicine, University of Miyazaki, 5200 Kiyotake, Miyazaki 889-1692, \\ Japan \\ 5) Division of Microbiology, Department of Infectious Diseases, Faculty of Medicine, University of Miyazaki, 5200 Kiyotake, Miyazaki \\ 889-1692, Japan \\ 6)Division of Bioenvironmental Science, Frontier Science Research Center, University of Miyazaki, 5200 Kiyotake, Miyazaki 889-1692, Japan
}

(Received 15 October 2015/Accepted 8 December 2015/Published online in J-STAGE 20 December 2015)

ABSTRACT. Helicobacter cinaedi infection has been recognized as an increasingly important emerging disease in humans. Infection with $H$. cinaedi causes bacteremia, cellulitis and enteritis. H. cinaedi has been isolated from non-human sources, including dogs, cats and rodents; however, it remains unclear whether animal strains are pathogenic in humans and as zoonotic pathogens. In this study, $H$. cinaedi isolates were recovered from a dog and a hamster, and the ability of these isolates to adhere to, invade and translocate across polarized human intestinal epithelial Caco- 2 cells was examined in vitro. To better understand the pathogenic potential of animal $H$. cinaedi isolates, these results were compared with those for a human strain that was isolated from a patient with bacteremia. The animal and human strains adhered to and invaded Caco-2 cells, but to a lesser degree than the C. jejuni 81-176 strain, which was used as a control. The integrity of tight junctions was monitored by measuring transepithelial electrical resistance (TER) with a membrane insert system. The TER values for all $H$. cinaedi strains did not change during the experimental periods compared with those of the controls; however, translocation of $H$. cinaedi from the apical side to the basolateral side was confirmed by cultivation and $H$. cinaedi-specific PCR, suggesting that the $H$. cinaedi strains translocated by transcellular route. This study demonstrated that $H$. cinaedi strains of animal origin might have a pathogenic potential in human epithelial cells as observed in a translocation assay in vitro with a human isolate.

KEY WORDS: adherence, Caco-2 cell, Helicobacter cinaedi, invasion, translocation

doi: 10.1292/jvms.15-0595; J. Vet. Med. Sci. 78(4): 627-632, 2016

Helicobacter cinaedi, first recognized as a Campylobacter-like organism (CLO), is a Gram-negative, spiralshaped, motile, microaerobic bacterium and classified into enterohepatic Helicobacter species [25]. This organism was first isolated from homosexual men and was initially recognized as a rectal and intestinal pathogen among members of the population [25]. Since its isolation in humans, H. cinaedi has been considered an opportunistic pathogen that causes bacteremia, cellulitis, septicemia and enteritis in immunocompromised [2, 13, 19], immunocompetent and healthy persons $[10,15,18]$. Because $H$. cinaedi strains have been isolated from blood in humans $[15,19]$, the organism may be able to pass through the intestinal barrier. However, the

*Correspondence to: Misawa, N., Laboratory of Veterinary Public Health, Department of Veterinary Medical Science, Faculty of Agriculture, University of Miyazaki, 1-1 Gakuenkibanadai-nishi, Miyazaki 889-2192, Japan. e-mail: a0d901u@cc.miyazaki-u.ac.jp C2016 The Japanese Society of Veterinary Science

This is an open-access article distributed under the terms of the Creative Commons Attribution Non-Commercial No Derivatives (by-nc-nd) License $<$ http://creativecommons.org/licenses/by-nc-nd/4.0/>. epidemiological features of $H$. cinaedi, including its infectious sources and routes and pathogenesis, remain unclear.

According to epidemiological surveys, $H$. cinaedi has been isolated from non-human sources, such as dogs, cats, monkeys, hamsters and other rodents [4-6, 14, 26], which suggests that the organism may be widespread in a wide range of animal species. Therefore, these animals may be reservoirs for human infections $[4,6]$. However, the pathogenesis and epidemiological features of $H$. cinaedi strains of non-human origin are not fully understood. Therefore, we believe that it is important to determine whether animal strains of $H$. cinaed $i$ have pathogenic potential in humans as a zoonotic disease.

Bacterial infection using cultured mammalian cells in vitro is a useful tool for investigating host epithelial cellbacterium interactions, because a single population of organisms can be infected under defined conditions. These assays are simple and reproducible and allow for the quantification of both adherent and internalized bacteria. In this study, we compared the adherence, invasion and translocation ability of human and non-human $H$. cinaedi strains in polarized epithelial Caco-2 cells that were derived from the human intestine in vitro. 


\section{MATERIALS AND METHODS}

Bacterial strains: Three $H$. cinaedi strains were used in this study and have been previously described [27]. The N73 strain was isolated from the blood of a patient with bacteremia. The T22 and T34 strains were isolated from the feces of a healthy dog and hamster, respectively. The $H$. cinaedi CCUG $18818^{\mathrm{T}}$ strain was obtained from the Culture Collection at the University of Göteborg, Sweden and was used as a positive control for $H$. cinaedi-specific PCR. The Campylobacter jejuni 81-176 strain, which was originally obtained from a milk-borne outbreak in Minnesota [17], was used as a control, because its adherence to and invasion ability in intestinal epithelial Caco-2 cells has been well characterized [8, 11]. All of the bacterial strains were grown on Brucella agar (Becton, Dickinson and Co., Tokyo, Japan), which contained $5 \%$ defibrinated horse blood (Nippon Biotest Laboratories Inc., Tokyo, Japan), at $37^{\circ} \mathrm{C}$ for $2-3$ days under microaerobic conditions $\left(80 \% \mathrm{~N}_{2}, 10 \% \mathrm{CO}_{2}, 5 \% \mathrm{O}_{2}\right.$ and $\left.5 \% \mathrm{H}_{2}\right)$.

All of the isolates were suspended in Brucella broth (Becton, Dickinson and Co.), which contained 10\% (v/v) glycerol (Kanto Kagaku, Tokyo, Japan), and stored at $-80^{\circ} \mathrm{C}$ until testing. Before use in experiments, the bacteria were grown on Brucella agar, which was supplemented with 5\% defibrinated horse blood, at $37^{\circ} \mathrm{C}$ for $2-3$ days under microaerobic conditions as previously described.

Cell culture: Caco-2 (human colon carcinoma) cells were obtained from the RIKEN BioResource Centre Cell Bank (Tsukuba, Japan) and were routinely cultured in Eagle's minimum essential medium (EMEM; Nacalai Tesque, Kyoto, Japan), which was supplemented with $10 \%$ fetal bovine serum (FBS; NICHIREI BIOSCIENCES INC., Tokyo, Japan) and contained $50 \mu \mathrm{g} / \mathrm{m} l$ kanamycin (Sigma-Aldrich Japan, Tokyo, Japan), at $37^{\circ} \mathrm{C}$ under a $5 \% \mathrm{CO}_{2}$ humidified atmosphere.

Adherence and invasion assays: The adherence and invasion assays were performed according to the method by Konkel et al. [16] with several modifications. Briefly, $3 \times 10^{5}$ Caco-2 cells were added to each well of a 24-well microplate (ASAHI GLASS Co., Ltd., Tokyo, Japan), and the cells were incubated at $37^{\circ} \mathrm{C}$ for $24 \mathrm{hr}$ under $5 \% \mathrm{CO}_{2}$ in a humidified atmosphere. An aliquot of $500 \mu l$ of bacterial suspension was added to the cells at a multiplicity of infection (MOI) of 100, and the suspension was co-incubated with semiconfluent monolayers of Caco-2 cells with EMEM, which was supplemented with 1\% FBS but no antibiotics. The infected monolayers were not centrifuged after inoculation of the bacterial cells. The microplates were incubated at $37^{\circ} \mathrm{C}$ for 2 $\mathrm{hr}$ in a $5 \% \mathrm{CO}_{2}$ humidified atmosphere to allow the bacteria to adhere to and invade the cells. Then, the monolayers were washed three times with $1 \mathrm{ml}$ of EMEM that contained $1 \%$ FBS. Fresh EMEM that contained 10\% FBS and $250 \mu \mathrm{g} /$ $\mathrm{m} l$ of gentamicin (Sigma-Aldrich Japan) was added to half of the wells for the enumeration of intracellular bacteria after incubation at $37^{\circ} \mathrm{C}$ for $3 \mathrm{hr}$ in a $5 \% \mathrm{CO}_{2}$ humidified atmosphere. In preliminary experiments, all of the bacterial strains were killed after a 3-hr exposure of $250 \mu \mathrm{g} / \mathrm{m} l$ of gentamicin. Medium without antibiotics was added to the other half of the wells to enumerate the number of intracellular and extracellular bacteria. Following incubation, the monolayers were washed three times with $100 \mathrm{mM}$ phosphate buffer saline (PBS), pH 7.4 and lysed with $0.01 \%$ sodium desoxycholate (Nacalai Tesque). The suspensions were diluted, and viable bacteria were determined by counting the number of colonies on Brucella agar plates that contained $5 \%$ defibrinated horse blood after incubation at $37^{\circ} \mathrm{C}$ for $2-3$ days under microaerobic conditions as described above. The number of adhered cells was expressed as the number of intracellular and extracellular bacteria after subtracting the number of intracellular bacteria. Results were expressed as the mean \pm the standard deviation of bacteria adhering to and invading Caco-2 cells for three determinations.

Analysis of epithelial barrier integrity: Approximately $1 \times$ $10^{5}$ of Caco- 2 cells were suspended in EMEM that contained $10 \% \mathrm{FBS}$ and $50 \mu \mathrm{g} / \mathrm{m} l$ of kanamycin and were seeded onto $0.33-\mathrm{cm}^{2}$ cell culture inserts with a pore size of $3.0 \mu \mathrm{m}$ (Merck Millipore, Darmstadt, Germany) in 24-well microplates at $37^{\circ} \mathrm{C}$ for $7-10$ days in a $5 \% \mathrm{CO}_{2}$ humidified atmosphere. The medium was changed twice a week. The integrity of tight junctions was monitored by measuring transepithelial electrical resistance (TER) using a Millicell Electrical Resistance System (Merck Millipore). TER was measured as ohms $(\Omega) \times \mathrm{cm}^{2}$, and fluid resistance was subtracted. When the TER value reached maximal polarity $\left(>330 \Omega / \mathrm{cm}^{2}\right)$ after 7-10 days of incubation, the monolayers were washed three times with PBS. Then, approximately $2-5 \times 10^{6} \mathrm{cfu}$ of $H$. cinaedi, suspended in $200 \mu \mathrm{l}$ of EMEM containing 1\% FBS without antibiotics, was inoculated into the apical side of the monolayer. The culture medium in the basolateral side was replaced with $1 \mathrm{~m} l$ of EMEM that contained $1 \%$ FBS without antibiotics. The TER values were measured at 6 , 12 and $24 \mathrm{hr}$ after infection. The TER values for the cellfree control well were subtracted from the obtained values to remove background values. The cell culture inserts that were not inoculated with bacterium were used as a negative control. The assay was tested at least three times in triplicate.

Deteciton of $H$. cinaedi cells in the basolateral compartment of the cell culture insert: To determine whether the $H$. cinaedi strains translocated across the monolayer of Caco2 cells on a transmembrane of the cell culture insert, the bacterial cells in the medium of the basolateral side were harvested by centrifugation at $10,000 \times g$ for 10 min after a predetermined inoculation time. The precipitation was resuspended in $100 \mu \mathrm{l}$ of PBS, and $100 \mu \mathrm{l}$ of the suspension was inoculated on Brucella agar plates that contained 5\% defibrinated horse blood and incubated at $37^{\circ} \mathrm{C}$ for $2-3$ days under microaerobic conditions as described above. The bacterial DNA from $100 \mu l$ of the suspension was extracted using the DNeasy Blood, and Tissue Kit (Qiagen, Tokyo, Japan) was used according to the manufacturer's instructions. The PCR amplification of the $c d t$ gene, which encodes cytolethal distending toxin, was used to specifically detect $H$. cinaedi [24]. The partial $c d t$ gene $(410 \mathrm{bp})$ of $H$. cinaedi was amplified with the primers CDT F (5'- CTCGTCCGGATATGGTG $-3^{\prime}$ ) and CDT R (5'- AGAGTTCCCTATCACTGC -3'), which were designed based on the $c d t$ gene-sequence in $H$. 
cinaedi (accession number AB275331). PCR was performed in a final reaction volume of $20 \mu \mathrm{l}$. Each reaction contained $20 \mathrm{pM}$ of each primer (forward and reverse), $200 \mu \mathrm{M}$ of each deoxynucleoside triphosphate, $0.5 \mathrm{U}$ of Taq DNA polymerase (Qiagen), 1× PCR buffer and $2 \mu l$ of extracted DNA. The thermal cycling conditions included 30 cycles of denaturation at $94^{\circ} \mathrm{C}$ for $30 \mathrm{sec}$, annealing at $58^{\circ} \mathrm{C}$ for $30 \mathrm{sec}$ and extension at $72^{\circ} \mathrm{C}$ for $1 \mathrm{~min}$, followed by a final extension at $72^{\circ} \mathrm{C}$ for $10 \mathrm{~min}$. The specific amplification of each target gene was confirmed by $2 \%$ agarose gel electrophoresis.

Immunization of rabbit for $H$. cinaedi antibody production: Polyclonal antisera against $H$. cinaedi were prepared with 2-month-old New Zealand white rabbits. In brief, the rabbits were inoculated intracutaneously with each emulsified mixture of bacterial suspension and Freund's incomplete adjuvant (Nacalai Tesque) on three different days with 2-week intervals. Two weeks after the third immunization, whole blood was collected from the immunized rabbits. The collected serum was inactivated by incubation at $56^{\circ} \mathrm{C}$ for $30 \mathrm{~min}$ in a water bath and was stored in aliquots at $-20^{\circ} \mathrm{C}$ until use. The protocol was approved by the committee on animal experiment at the University of Miyazaki (acceptation number; 2007-025-6).

Fluorescence microscopy: To observe internalized $H$. cinaedi in Caco-2 cells after invasion, an immunofluorescence procedure was performed. Trypsinized $1 \times 10^{5}$ Caco- 2 cells were placed into each well of a chamber slide (Nalgene Nunc, Rochester, NY, U.S.A.) and incubated at $37^{\circ} \mathrm{C}$ for 3 days under $5 \% \mathrm{CO}_{2}$ in humidified atmosphere. The optical density at $550 \mathrm{~nm}$ of the $H$. cinaedi bacterial suspensions (N73, T22 and T34) was adjusted to 0.1 (contained approximately $1 \times 10^{7} \mathrm{cfu} / \mathrm{m} l$ ) in antibiotic-free EMEM, which was supplemented with $10 \%$ FBS. Then, $500 \mu l$ of each bacterial suspension was inoculated into the cell monolayers, which were prewashed twice with PBS. The cell monolayers were incubated at $37^{\circ} \mathrm{C}$ for $24 \mathrm{hr}$ in a $5 \% \mathrm{CO}_{2}$ humidified atmosphere. Then, the cell monolayers were fixed using $4 \%$ paraformaldehyde in PBS and permeabilized using $0.1 \%$ Triton X-100 (Nacalai Tesque) with $0.5 \%$ bovine serum albumin (Sigma-Aldrich Japan). H. cinaedi that adhered to and invaded Caco- 2 cells were labeled with rabbit anti- $H$. cinaed $i$ serum $(1: 200)$ at $25^{\circ} \mathrm{C}$ for $1 \mathrm{hr}$, and goat anti-rabbit antibodies conjugated with fluorescein isothiocyanate (FITC) $(7.5 \mu \mathrm{g} / \mathrm{ml})$ (Invitrogen, Carlsbad, CA, U.S.A.) were added. Rhodamine phalloidin $(1 \mathrm{U} / \mathrm{m} l)$ (Invitrogen) was added to detect the actin of Caco- 2 cells. Internalized bacteria in Caco- 2 cells were visualized by three-dimensional analysis using the fluorescence microscope BIOREVO BZ-9000 (KEYENCE, Osaka, Japan).

Statistical analysis: The results were expressed as the mean \pm the standard deviation for every experiment, which were performed in triplicate. The statistical analysis was performed using Student's $t$-test. Statistical significance was defined as $P<0.05$.

\section{RESULTS}

Adherence and invasion in Caco-2 cells: All of the $H$. cinaedi strains adhered to and invaded Caco-2 cells regardless of their origin (Table 1). However, the number of $H$. cinaedi that adhered to and invaded Caco-2 cells was lower than that of $C$. jejuni. The number of adherent and internalized bacterial cells was compared among the tested strains. Strain N73, which was isolated from a patient with bacteremia, adhered to and invaded Caco- 2 cells in greater numbers ( $10^{6} \mathrm{cfu}$ for adhesion and $10^{4} \mathrm{cfu}$ for invasion, respectively) compared with the canine strain T22 $\left(10^{5}\right.$ cfu for adhesion and $10^{3} \mathrm{cfu}$ for invasion) and the hamster strain T34 $\left(10^{4} \mathrm{cfu}\right.$ for adhesion and $10 \mathrm{cfu}$ for invasion).

Analysis of epithelial barrier integrity: The ability of $H$. cinaedi strains to translocate across epithelial cells was examined in polarized Caco-2 cell monolayers using a membrane insert system. TER across polarized monolayers of the Caco- 2 cells was not affected by any of the $H$. cinaed $i$ strains during the experimental period, which was similarly observed for the negative control and C. jejuni (Fig. 1A). Migration of $H$. cinaedi from the apical side to the basolateral side was confirmed at $6 \mathrm{hr}$ after the inoculation by cultivation and $H$. cinaedi-specific PCR using the basolateral medium (Fig. 1B and 1C), and all of the $H$. cinaedi strains examined were recovered from the basolateral medium by cultivation and PCR during $24 \mathrm{hr}$ observed (Fig. 1C).

Internalization of $H$. cinaedi in Caco-2 cells: To confirm the internalization of $H$. cinaedi in Caco- 2 cells, the monolayers were infected with the three $H$. cinaedi strains for $24 \mathrm{hr}$, and cell internalization was visualized using a fluorescence microscope. The presence of $H$. cinaedi strains in Caco-2 cells was observed in the cross-section of the X-, Y- and Z-axes (Fig. 2). Regardless of the isolate origin, all of the $H$. cinaedi strains exhibited invasion potential in Caco-2 cells.

\section{DISCUSSION}

Several researchers reported that direct contact with pets that harbor $H$. cinaedi may be a possible route of infection in humans [13, 20, 23]. However, data on the pathogenesis and epidemiology of animal $H$. cinaedi strains, including zoonotic transmission routes between animals and humans, are not fully understood. Despite the high prevalence of $H$. cinaedi in hamsters [6], intestinal disease does not occur following naturally acquired infection. Therefore, $H$. cinaedi may behave as a commensal in animal hosts, because clinical and pathological observations have not been reported. Misawa et al. [21] reported that the $H$. cinaedi strain 94105 was isolated from a 2-month-old female puppy with bloody diarrhea. In this case, the diarrhea episodes occurred repeatedly after antibiotic treatment, and $H$. cinaedi was isolated from the puppy each time. However, because Campylobacter upsaliensis, Helicobacter bilis and Anaerobiospirillum spp. were simultaneously isolated, it is unclear whether $H$. cinaedi was the direct cause of the diarrhea. Therefore, the pathogenesis of $H$. cinaedi that is isolated from animals has been controversial. This lack of knowledge has confounded the prevention and treatment of this infection.

To investigate the host epithelial cell-enteric bacterium 
Table 1. The numbers of viable H. cinaedi and C. jejuni that adhered to and invaded Caco-2 cells

\begin{tabular}{llccc}
\hline Strain & Origin & $\begin{array}{c}\text { The number of viable that inoculated } \\
\text { per well in a 24-well plate }\end{array}$ & $\begin{array}{c}\text { The number of viable that adhered to } \\
\text { cells per well in a 24-well plate }\end{array}$ & $\begin{array}{c}\text { The number of viable that invaded } \\
\text { cells per well in a 24-well plate }\end{array}$ \\
\hline N73 & human & $1.35 \times 10^{8}$ & a) $(1.32 \pm 0.29) \times 10^{6}$ & $(4.40 \pm 0.14) \times 10^{4}$ \\
T22 & dog & $4.90 \times 10^{7}$ & $(3.38 \pm 1.37) \times 10^{5}$ & $(9.00 \pm 1.44) \times 10^{3}$ \\
T34 & cat & $5.27 \times 10^{7}$ & $(2.33 \pm 0.81) \times 10^{4}$ & $(1.67 \pm 1.15) \times 10$ \\
$81-176$ & human & $6.45 \times 10^{7}$ & $(1.59 \pm 0.40) \times 10^{6}$ & $(3.88 \pm 0.42) \times 10^{5}$ \\
\hline
\end{tabular}

a) The results were expressed as the mean \pm the standard deviation for every experiment, which were performed in triplicate.

A

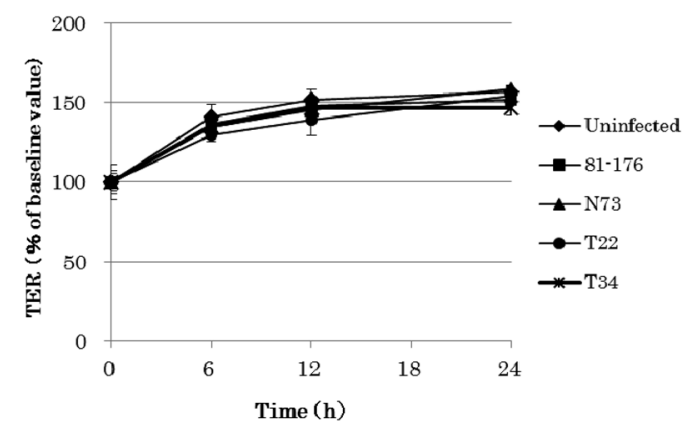

B

\begin{tabular}{cccc}
\hline \multirow{2}{*}{ Strain } & \multicolumn{3}{c}{ Time (h) } \\
\cline { 2 - 4 } & 6 & 12 & 24 \\
\hline Uninfected & - & - & - \\
$81-176$ & + & + & + \\
N73 & + & + & + \\
T22 & + & + & + \\
T34 & + & + & + \\
\hline
\end{tabular}

C

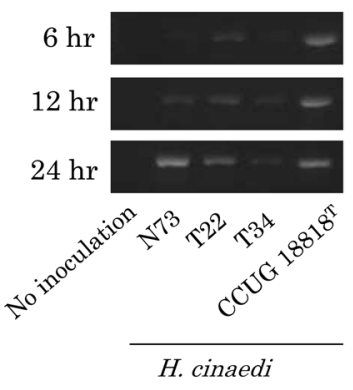

Fig. 1. Transepithelial electrical resistance (TER) in Caco-2 cells infected with H. cinaedi. (A) TER was determined at $0,6,12$ and $24 \mathrm{hr}$ after infection. The values are expressed as the percentage of TER immediately before bacterial inoculation. The values are the mean $(n=3) \pm$ standard deviation. One representative, in triplicate, of three experiments is shown. The differences from the control at each observation point were not significant. (B) The presence of $C$. jejuni and H. cinaedi that migrated from the apical side to the basolateral side during cultivation on the basolateral medium was expressed as: -, not detected; or +, detected. (C) H. cinaedi that migrated from the apical side to the basolateral side was detected using a $H$. cinaedi-specific PCR with DNA that was extracted from the basolateral medium. The CCUG $18818^{\mathrm{T}}$ strain was used as a positive control for $H$. cinaedi-specific PCR.

A

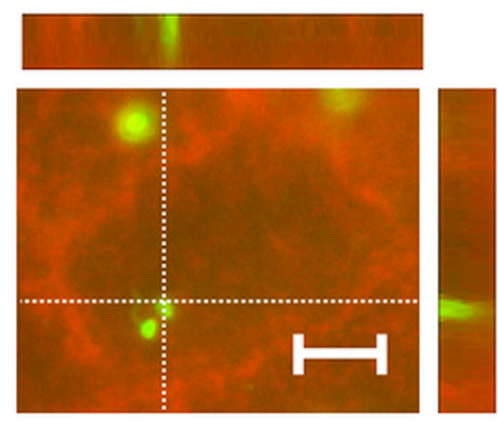

B

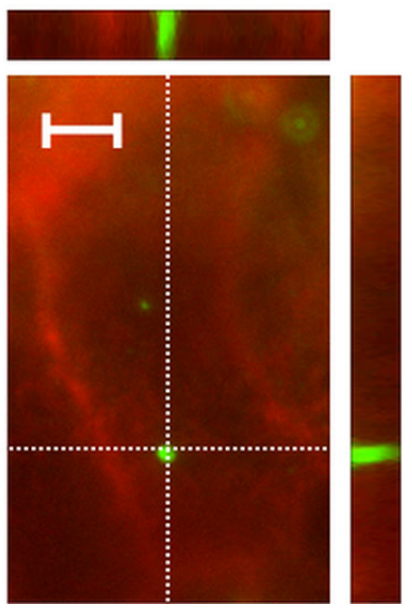

C

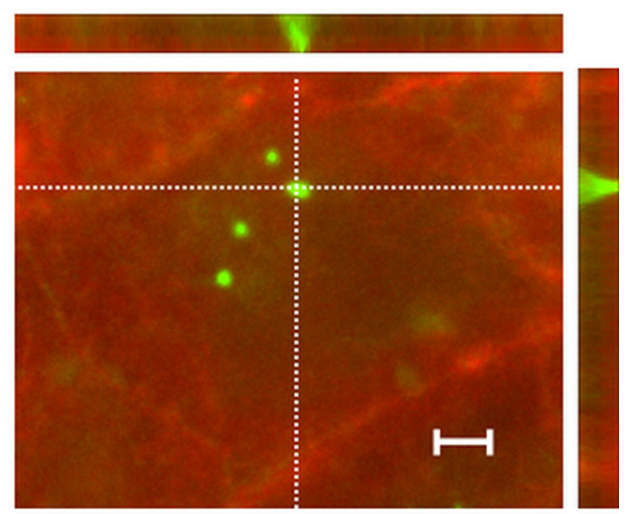

Fig. 2. Three-dimensional images of Caco-2 cell monolayers infected with $H$. cinaedi at $24 \mathrm{hr}$ post inoculation using a fluorescence microscope (Z-axis scans, XY plane). Cytoskeletal actin is stained red with rhodamine phalloidin. $H$. cinaedi is stained green using an anti- $H$. cinaedi antibody and FITC-conjugated goat anti-rabbit antibody. The scale bars represent $10 \mu \mathrm{m}$. (A) The N73 strain of human origin in Caco-2 cells, (B) The T23 strain of canine origin in Caco-2 cells, (C) The T34 strain of hamster origin in Caco-2 cells. 
interaction, Caco-2 cells are commonly used as a simple model. Caco-2 cells are derived from transformed human colonic carcinoma cells, which are polarized monolayers that have intercellular tight junctions and defined apical and basolateral structures $[9,12]$. This study was conducted to better understand the pathogenesis of $H$. cinaed $i$ strains that are isolated from animals using this in vitro model. Potential virulence factors that may play a role in the pathogenesis of $H$. cinaedi include adherence, invasion and translocation across the mucosal epithelial barrier. This study demonstrated that a human $H$. cinaedi strain and $H$. cinaedi strains isolated from a dog and hamster exhibited adherence and invasion potential in human epithelial cells in vitro. This finding was similarly observed in the $C$. jejuni strain 81-176, whose adhesion and invasion potential in Caco-2 cells has been well characterized (Table 1). However, as compared with $C$. jejuni, which is a causative microorganism of food-borne infections, the number of adhering and invading $H$. cinaedi cells was low. Therefore, the adherence and invasion ability of $H$. cinaedi in Caco- 2 cells may be lower than that of $C$. jejuni. In addition, the adherence and invasion ability of the T34 strain, which was isolated from a hamster, was lower than those of canine and human strains. These differences may be attributed to pathogenic abilities, such as motility; the characteristics of the bacterial surface, which depend on the type of species which the strains are derived or the experimental conditions, such as the MOI [15]. Additional studies using more strains under different experimental conditions are needed; however, the finding that animal strains have the same pathogenic potential as a human strain is more important than a comparison of the pathogenic abilities among animal strains.

The possible pathways that $H$. cinaedi uses to penetrate the intestinal mucosa are considered transcellular and/or paracellular routes [1]. The ability of the human and animal $H$. cinaedi strains to translocate across the epithelial cell barrier was examined in polarized Caco- 2 cell monolayers by measuring TER (Fig. 1). TER is used frequently as an index of tight junction permeability and monolayer integrity. When bacteria use the intercellular route from the apical to basolateral cell surface, the tight junction is disrupted and TER decreases [3]. In this study, none of the $H$. cinaedi strains were associated with a decrease in TER after $24 \mathrm{hr}$ of infection as seen in C. jejuni 81-176, which can translocate from the apical side to the basorateral side of polarized Caco- 2 cells without varying TER value [28], indicating that $H$. cinaedi did not disrupt the tight junctions of Caco-2 cells. Whereas the bacteria inoculated into the apical side were isolated from basolateral medium 6,12 and $24 \mathrm{hr}$ after inoculation (Fig. 1B). Furthermore, a partial $c d t$ gene-fragment, which was specific to the $H$. cinaedi strains, was detected by PCR in the basolateral medium (Fig. 1C). This finding suggests that $H$. cinaedi uses transcellular translocation and has transcytotic ability. During transcytosis, pathogens invade epithelial cells, migrate across the cytoplasm and egress from the opposite surface. To confirm the internalization of $H$. cinaedi in Caco-2 cells, the monolayers were infected with the three $H$. cinaedi strains, and internalization was visualized using immunofluorescent techniques. As expected, all of the $H$. cinaedi strains were observed in Caco-2 cells regardless of the origin (Fig. 2). These observations suggest that $H$. cinaedi strains might migrate by transcellular translocation.

This study demonstrated that animal strains have the adhesion and invasion ability as seen in human strains, especially isolates from a dog and a hamster, which are common companion animals. This report is the first on the pathogenesis of $H$. cinaedi using polarized intestinal epithelial Caco-2 cells in vitro. The in vitro pathogenic potential may explain human clinical cases of bacteremia, cellulitis and septicemia $[2,13,18,19]$. To data, no reliable epidemiological evidence of the zoonotic potential of $H$. cinaedi has been published. Therefore, further investigations are needed to determine the epidemiology and infection sources of animal $H$. cinaedi strains in humans.

The whole genome of $H$. cinaedi has recently been reported, and several pathogenic genes were present in the genome. HCN_1887 (fibronectin/fibrinogen-binding protein) and ciaB (Campylobacter invasion antigens) may determine the adherence and invasion abilities of $H$. cinaedi $[7,22]$. Investigating the presence of pathogenic genes in animal $H$. cinaedi strains, and clarifying their functions would lead to a better understanding pathogenesis of $H$. cinaedi in both animals and humans.

ACKNOWLEDGMENT. This work was supported by a grant from a subproject of integrated research projects for medicine and veterinary medicine in University of Miyazaki.

\section{REFERENCES}

1. Backert, S., Boehm, M., Wessler, S. and Tegtmeyer, N. 2013. Transmigration route of Campylobacter jejuni across polarized intestinal epithelial cells: paracellular, transcellular or both? Cell Commun. Signal. 11: 72-86. [Medline] [CrossRef]

2. Burman, W. J., Cohn, D. L., Reves, R. R. and Wilson, M. L. 1995. Multifocal cellulitis and monoarticular arthritis as manifestations of Helicobacter cinaedi bacteremia. Clin. Infect. Dis. 20: 564-570. [Medline] [CrossRef]

3. Chen, M. L., Ge, Z., Fox, J. G. and Schauer, D. B. 2006. Disruption of tight junctions and induction of proinflammatory cytokine responses in colonic epithelial cells by Campylobacter jejuni. Infect. Immun. 74: 6581-6589. [Medline] [CrossRef]

4. Comunian, L. B., Moura, S. B., Paglia, A. P., Nicoli, J. R., Guerra, J. B., Rocha, G. A. and Queiroz, D. M. 2006. Detection of Helicobacter species in the gastrointestinal tract of wild rodents from Brazil. Curr. Microbiol. 53: 370-373. [Medline] [CrossRef]

5. Fernandez, K. R., Hansen, L. M., Vandamme, P., Beaman, B. L. and Solnick, J. V. 2002. Captive rhesus monkeys (Macaca mulatta) are commonly infected with Helicobacter cinaedi. J. Clin. Microbiol. 40: 1908-1912. [Medline] [CrossRef]

6. Gebhart, C. J., Fennell, C. L., Murtaugh, M. P. and Stamm, W. E. 1989. Campylobacter cinaedi is normal intestinal flora in hamsters. J. Clin. Microbiol. 27: 1692-1694. [Medline]

7. Goto, T., Ogura, Y., Hirakawa, H., Tomida, J., Morita, Y., Akaike, T., Hayashi, T. and Kawamura, Y. 2012. Complete genome sequence of Helicobacter cinaedi strain PAGU611, isolated in a case of human bacteremia. J. Bacteriol. 194: 3744-3745. [Med- 
line] [CrossRef]

8. Harvey, P., Battle, T. and Leach, S. 1999. Different invasion phenotypes of Campylobacter isolates in Caco-2 cell monolayers. $J$. Med. Microbiol. 48: 461-469. [Medline] [CrossRef]

9. Hidalgo, I. J., Raub, T. J. and Borchardt, R. T. 1989. Characterization of the human colon carcinoma cell line (Caco-2) as a model system for intestinal epithelial permeability. Gastroenterology 96: 736-749. [Medline]

10. Holst, H., Andresen, K., Blom, J., Højlyng, N., Kemp, M., Krogfelt, K. A. and Christensen, J. J. 2008. A Case of Helicobacter cinaedi Bacteraemia in a Previously Healthy Person with Cellulitis. Open Microbiol. J. 2: 29-31. [Medline] [CrossRef]

11. Hu, L., Tall, B. D., Curtis, S. K. and Kopecko, D. J. 2008. Enhanced microscopic definition of Campylobacter jejuni 81-176 adherence to, invasion of, translocation across, and exocytosis from polarized human intestinal Caco-2 cells. Infect. Immun. 76: 5294-5304. [Medline] [CrossRef]

12. Hughson, E. J., Cutler, D. F. and Hopkins, C. R. 1989. Basolateral secretion of kappa light chain in the polarised epithelial cell line, Caco-2. J. Cell Sci. 94: 327-332. [Medline]

13. Kiehlbauch, J. A., Tauxe, R. V., Baker, C. N. and Wachsmuth, I. K. 1994. Helicobacter cinaedi-associated bacteremia and cellulitis in immunocompromised patients. Ann. Intern. Med. 121: 90-93. [Medline] [CrossRef]

14. Kiehlbauch, J. A., Brenner, D. J., Cameron, D. N., Steigerwalt, A. G., Makowski, J. M., Baker, C. N., Patton, C. M. and Wachsmuth, I. K. 1995. Genotypic and phenotypic characterization of Helicobacter cinaedi and Helicobacter fennelliae strains isolated from humans and animals. J. Clin. Microbiol. 33: 2940-2947. [Medline]

15. Kitamura, T., Kawamura, Y., Ohkusu, K., Masaki, T., Iwashita, H., Sawa, T., Fujii, S., Okamoto, T. and Akaike, T. 2007. Helicobacter cinaedi cellulitis and bacteremia in immunocompetent hosts after orthopedic surgery. J. Clin. Microbiol. 45: 31-38. [Medline] [CrossRef]

16. Konkel, M. E. and Joens, L. A. 1990. Effect of enteroviruses on adherence to and invasion of HEp-2 cells by Campylobacter isolates. Infect. Immun. 58: 1101-1105. [Medline]

17. Korlath, J. A., Osterholm, M. T., Judy, L. A., Forfang, J. C. and Robinson, R. A. 1985. A point-source outbreak of campylobacteriosis associated with consumption of raw milk. J. Infect. Dis. 152: 592-596. [Medline] [CrossRef]

18. Lasry, S., Simon, J., Marais, A., Pouchot, J., Vinceneux, P. and Boussougant, Y. 2000. Helicobacter cinaedi septic arthritis and bacteremia in an immunocompetent patient. Clin. Infect. Dis. 31: 201-202. [Medline] [CrossRef]
19. Matsumoto, T., Goto, M., Murakami, H., Tanaka, T., Nishiyama, H., Ono, E., Okada, C., Sawabe, E., Yagoshi, M., Yoneyama, A., Okuzumi, K., Tateda, K., Misawa, N. and Yamaguchi, K. 2007. Multicenter study to evaluate bloodstream infection by Helicobacter cinaedi in Japan. J. Clin. Microbiol. 45: 2853-2857. [Medline] [CrossRef]

20. Minauchi, K., Takahashi, S., Sakai, T., Kondo, M., Shibayama, K., Arakawa, Y. and Mukai, M. 2010. The nosocomial transmission of Helicobacter cinaedi infections in immunocompromised patients. Intern. Med. 49: 1733-1739. [Medline] [CrossRef]

21. Misawa, N., Kawashima, K., Kondo, F., Kushima, E., Kushima, K. and Vandamme, P. 2002. Isolation and characterization of Campylobacter, Helicobacter, and Anaerobiospirillum strains from a puppy with bloody diarrhea. Vet. Microbiol. 87: 353-364. [Medline] [CrossRef]

22. Miyoshi-Akiyama, T., Takeshita, N., Ohmagari, N. and Kirikae, T. 2012. Complete genome sequence of Helicobacter cinaedi type strain ATCC BAA-847. J. Bacteriol. 194: 5692. [Medline] [CrossRef]

23. Orlicek, S. L., Welch, D. F. and Kuhls, T. L. 1993. Septicemia and meningitis caused by Helicobacter cinaedi in a neonate. $J$. Clin. Microbiol. 31: 569-571. [Medline]

24. Oyama, K., Khan, S., Okamoto, T., Fujii, S., Ono, K., Matsunaga, T., Yoshitake, J., Sawa, T., Tomida, J., Kawamura, Y. and Akaike, T. 2012. Identification of and screening for human Helicobacter cinaedi infections and carriers via nested PCR. $J$. Clin. Microbiol. 50: 3893-3900. [Medline] [CrossRef]

25. Quinn, T. C., Goodell, S. E., Fennell, C., Wang, S. P., Schuffler, M. D., Holmes, K. K. and Stamm, W. E. 1984. Infections with Campylobacter jejuni and Campylobacter-like organisms in homosexual men. Ann. Intern. Med. 101: 187-192. [Medline] [CrossRef]

26. Recordati, C., Gualdi, V., Craven, M., Sala, L., Luini, M., Lanzoni, A., Rishniw, M., Simpson, K. W. and Scanziani, E. 2009. Spatial distribution of Helicobacter spp. in the gastrointestinal tract of dogs. Helicobacter 14: 180-191. [Medline] [CrossRef]

27. Taniguchi, T., Sekiya, A., Higa, M., Saeki, Y., Umeki, K., Okayama, A., Hayashi, T. and Misawa, N. 2014. Rapid identification and subtyping of Helicobacter cinaedi strains by intactcell mass spectrometry profiling with the use of matrix-assisted laser desorption ionization-time of flight mass spectrometry. $J$. Clin. Microbiol. 52: 95-102. [Medline] [CrossRef]

28. Van Deun, K., Pasmans, F., Van Immerseel, F., Ducatelle, R. and Haesebrouck, F. 2008. Butyrate protects Caco-2 cells from Campylobacter jejuni invasion and translocation. Br. J. Nutr. 100: 480-484. [Medline] [CrossRef] 